\title{
Life cycle carbon emission of monorail transit and its comparison in operation stage with other city transit modes
}

\author{
Teng $\mathrm{Li}^{1}$, Eryu $\mathrm{Zhu}^{1 *}$, Haoran $\mathrm{Liu}^{1}$ \\ ${ }^{1}$ Dept. of Civil Engineering., Beijing Jiaotong University., Shangyuancun 3rd, Beijing, China, 100044 \\ ${ }^{*}$ Corresponding author, Eryu Zhu, Professor of Bridge Department, Beijing Jiaotong University, Ph. D, China.
}

\begin{abstract}
In this paper, carbon emissions of a monorail transit are calculated using the method of whole life cycle, which can be divided into four stages: material manufacturing stage, construction stage, operation stage and demolition stage. In the operation phase, the units are PKT (Passenger Kilometers Travelled) and VKT (Vehicle Kilometers Travelled), while in other three stages, the unit is $1 \mathrm{~km}$. The results show that the carbon emissions from the $1 \mathrm{~km}$ length monorail are 6271.204 tons. In addition, in the operation stage, it is found that the PKT index and VKT index of Chongqing monorail transportation are 0.07468 and 3.31933 respectively, far lower than those of subways in the same city. For PKT indicators of other rail transits, from small to large, they are light rail, tram, subway, APM and maglev. As for VKT indicators, from small to large, they are tram, light rail, subway, APM and maglev. The PKT index of Beijing subway is the lowest compared with that of other cities.
\end{abstract}

\section{Introduction}

In recent years, with the continuous increase of urban population density, the flow of people and goods between cities and the construction of rail transit are in full swing. However, with the continuous expansion of the construction scale of different types of rail transit, the topic of environmental pollution, which is closely related to the life quality of residents, begins to receive the close attention of the country and the society. The increasing carbon emission has posed a threat to human lives in the world. In this year, the concept of carbon neutrality and carbon peak was first written into the government work report in China [1]. Carbon peak means that China promises that carbon emissions will stop growing by 2030 and gradually decline after they peak. Carbon neutrality means that enterprises, groups or individuals calculate the total amount of greenhouse gas emissions directly or indirectly generated within a certain period of time, and then offset the carbon emission generated by themselves through plant afforestation, energy conservation and emission reduction, etc., so as to achieve the goal of zero emission.

According to statistics [2], carbon emission from China's transportation industry accounts for nearly $10 \%$ of China's total carbon emissions. And with the advancement of urbanization and industrialization, the carbon emissions from China's transportation industry will continue to increase. Therefore, the development of green transportation has a very great significance. However, there has been little analysis of the carbon emissions of different modes of transport. In this paper, carbon emissions from different urban transit modes are calculated and compared, including monorail transit, subway, maglev, APM and trams, to find a lower carbon emission transit mode, and to facilitate the adjustment of the urban rail transit system and urban sustainable development, and to provide suggestions for government policies.

\section{Whole life cycle carbon emission}

The carbon emission calculated in this paper is based on the method of whole life cycle, and the carbon emission of different traffic projects is divided into the following four stages: material manufacturing stage, construction stage, operation stage and demolition stage [3]. The corresponding list is established for each stage, and carbon emissions of each item in the list are calculated. The carbon emissions of the whole life cycle are obtained by summing up the carbon emissions of the four stages.

\subsection{Carbon emission calculation methods in each stage}

The calculation method of carbon emission in each stage [4] is as follows.

In the material manufacturing stage, the following formula is used:

$$
M_{c}=\sum M_{i} \times C_{i}
$$

$M_{c}$ is the carbon emission in the production and processing stage of building materials; $M_{i}$ is the consumption of the ith material in the production and processing stage of building materials; $C_{i}$ is the carbon emission of the production process of unit building materials. 
In the construction stage, greenhouse gas emissions mainly come from the transportation of materials and different construction works, and results are related to the transportation distance of building materials and the amount of works in each process. The following formula will be used to calculate carbon emissions in the construction stage:

$$
C_{c}=\sum M_{i} \times C_{t i} \times L_{i}+M_{p} \times C_{p}
$$

$C_{c}$ is the carbon emission in the construction stage; $M_{i}$ is the amount of the ith material in the construction stage; $C_{t i}$ is the carbon emission per unit transportation distance of the vehicle; $L_{i}$ is the transportation distance. $M_{p}$ is the amount of works in each process in the construction stage and $C_{p}$ is the carbon emission generated by unit work in each process.

In the operation stage, energy consumption mainly comes from the electricity consumed during vehicle operation, while carbon emission mainly comes from electricity production. The following formula is used to calculate carbon emission in this stage:

$$
O_{c}=\sum M_{i} \times C_{i}
$$

$O_{c}$ is the carbon emission in the construction stage; $M_{i}$ is the electricity consumed during operation in the life cycle of different urban transit modes, and $C_{i}$ is the carbon emission generated by production of unit electricity.

In the demolition stage, the following formula is used to calculate carbon emission:

$$
D_{c}=\sum M_{i} \times C_{t i} \times L_{i}+M_{p} \times C_{p}
$$

$D_{c}$ is the carbon emission in the demolition stage; $M_{i}$ is the amount of the ith material in the construction stage; $C_{t i}$ is the carbon emission per unit transportation distance of the vehicle; $L_{i}$ is the transportation distance. $M_{p}$ is the amount of works in each process in the demolition stage and $C_{p}$ is the carbon emission generated by unit work in each process.

\subsection{Carbon emission factors}

Energy consumption carbon emission factor refers to the amount of greenhouse gases associated with the consumption of unit mass energy, and is an important parameter representing the characteristics of greenhouse gas emissions of a certain energy type [5]. Carbon emission factors of IPCC 2006 [6] are used in this paper. The carbon emission factor of diesel is $3.16 \mathrm{~kg} \mathrm{CO} / \mathrm{kg}$. The average carbon emission factor of electricity production in China is $1.062 \mathrm{~kg} \mathrm{CO}_{2}$ / kilowatt-hour [7].

According to some research results [8-10], carbon emission from C40 concrete is $644.59 \mathrm{~kg} / \mathrm{m}^{3}$; carbon emissions of 1-ton large size steel, medium and small size steel and steel wire are $20344.4 \mathrm{~kg} / \mathrm{ton}, 16883.7 \mathrm{~kg} / \mathrm{ton}$, $16706.3 \mathrm{~kg} / \mathrm{ton}$, respectively.

Carbon emissions in different works are mainly from the electricity consumption and diesel consumption from various construction machinery and equipment. Carbon emission of concrete construction process per unit volume [11] is shown in the following table:

Table 1. Carbon emission of concrete construction per unit volume.

\begin{tabular}{cccc}
\hline Procedure $\left(\mathrm{kg} / \mathrm{m}^{3}\right)$ & $\mathrm{CO}_{2}$ & $\mathrm{NO}$ & Carbon Equivalent \\
\hline Template Works & 46.975 & 0.377 & 159.321 \\
Steel Works & 13.947 & 0.427 & 141.193 \\
Concrete Works & 3.166 & $/$ & 3.166 \\
Earth Works & 8.89 & $/$ & 8.89 \\
\hline
\end{tabular}

\subsection{Carbon emission from material transportation}

In the material transportation process, carbon emissions are mainly caused by the energy consumed by transportation vehicles. Road transportation is the most common solution and the fuel of road vehicle is mainly diesel. In this paper, the specific assumptions for material transportation are as follows: for concrete, 8 square concrete mixers are used, and the fuel consumption per $100 \mathrm{~km}$ is $35 \mathrm{~L}$. As for other building materials such as steel, 20-ton freight vehicles are used, and the fuel consumption per $100 \mathrm{~km}$ is $30 \mathrm{~L}$. It is assumed that the round-trip transport distance of concrete is $30 \mathrm{~km}$, that of steel is $60 \mathrm{~km}$ and that of earthwork is $15 \mathrm{~km}$. In the structural demolition stage, only the removal of major materials such as concrete and steel are considered. It is assumed that the average transport distance of steel is $60 \mathrm{~km}$, and the transport distance of waste concrete is $30 \mathrm{~km}$.

\section{Estimation of life-cycle carbon emissions from monorail transit}

In this paper, $1 \mathrm{~km}$ is selected as a functional unit to carry out a theoretical analysis of carbon emissions of monorail transit in the four stages. A monorail transit line in China is selected for analysis. The cross section of concrete PC guideway running by the train is I-shaped, $850 \mathrm{~mm}$ wide, and $1.5 \mathrm{~m}$ high. The structure is shown in the figures below [12]: 


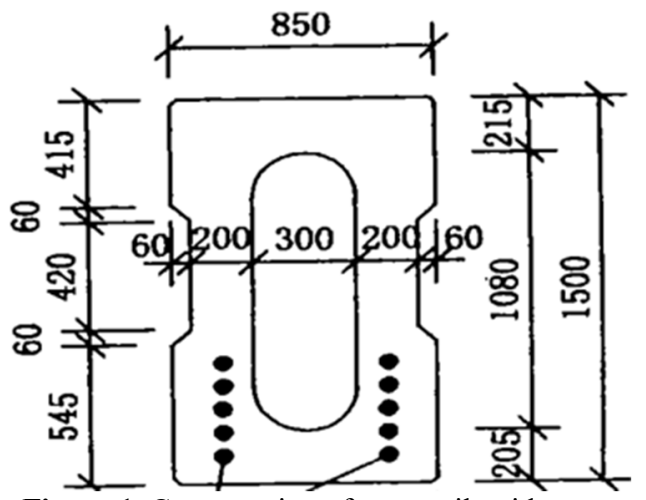

Figure 1. Cross section of monorail guideway
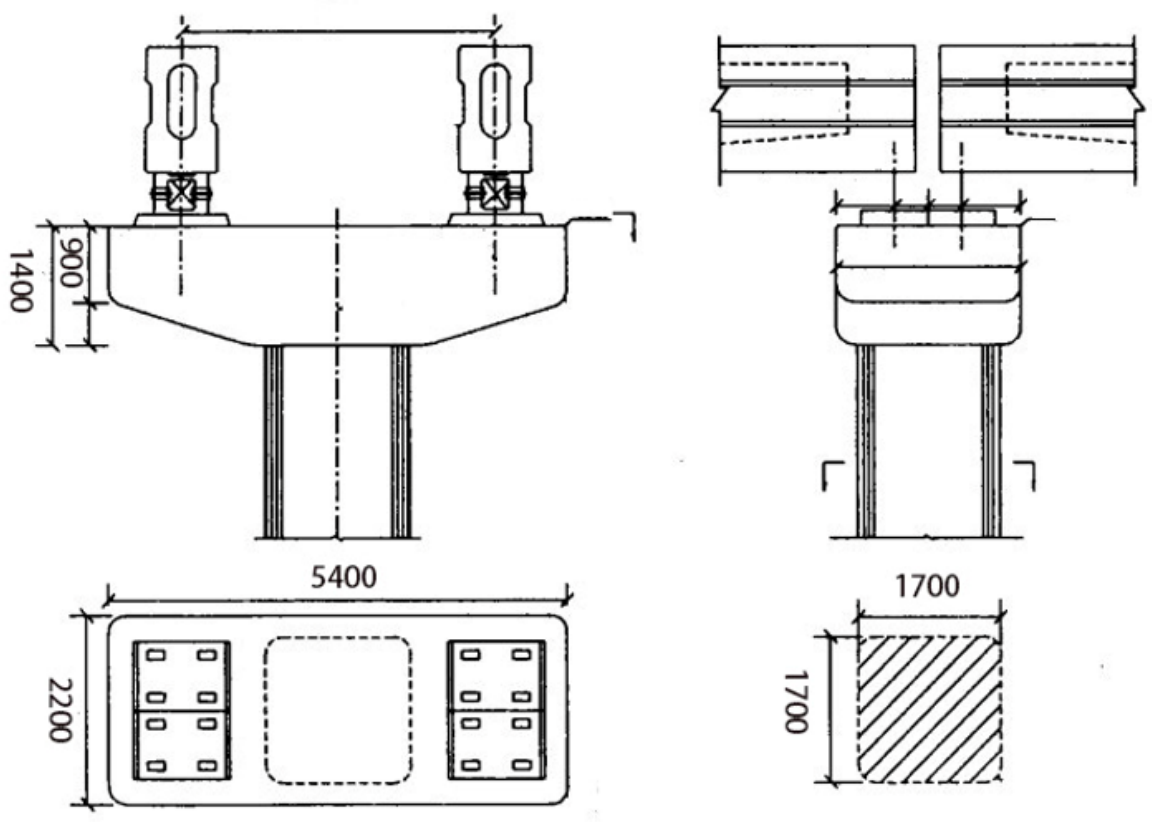

Figure 2. $\mathrm{T}$-shaped pier of monorail.

Assuming the length of a span is $25 \mathrm{~m}$ and the bridge pier height is $9 \mathrm{~m}$. There are 41 piers in $1 \mathrm{~km}$ length bridge and the concrete volume of two guideways, 41piers, 41 cover beams are $1912.8 \mathrm{~m}^{3}, 1066.4 \mathrm{~m}^{3}$ and $598.477 \mathrm{~m}^{3}$, respectively. Assuming the $\mathrm{C} 40$ concrete and 10 bunches of 3 - $7 \Phi 5$ steel strands are used in the guideway. Total steel strand volume in $1 \mathrm{~km}$ guideway is $8.2 \mathrm{~m}^{3}$. Total mass of $1 \mathrm{~km}$ steel strand is $64370 \mathrm{~kg}$. Assuming the reinforcement ratio of compression members is $0.2 \%$, and reinforcement ratio of flexural members is $0.2 \%$ too. Total steel mass is $56169.53 \mathrm{~kg}$. Assuming the spread foundations and piles are used and each pier has a single row of three piles, with diameter of each pile $100 \mathrm{~cm}$. Assuming the depth is $12 \mathrm{~m}$. The volume of concrete or earth is $1158.66 \mathrm{~m}^{3}$. Assuming the pile reinforcement ratio is $0.2 \%$, then the steel quantity is $18190.96 \mathrm{~kg}$.

In all, total concrete volume is $4736.36 \mathrm{~m}^{3}$. Total quantities of steel rebar and strand are $74360.49 \mathrm{~kg}$ and $64370 \mathrm{~kg}$, respectively. And total earth volume is 1158.66 $\mathrm{m}^{3}$. Based on the above carbon emission factors, carbon emissions from the material manufacturing stage, construction stage and material transportation in the construction stage are shown in Table 2, Table 3 and Table 4, respectively.

Table 2. Carbon emissions of monorail transit in material manufacturing stage.

\begin{tabular}{ccccc}
\hline & Concrete $\left(\mathrm{m}^{3}\right)$ & Steel strand $(\mathrm{kg})$ & Steel reinforcement $(\mathrm{kg})$ & Sum \\
\hline Carbon Emission & 4736.36 & 64370 & 74360.49 & 2659720.5 \\
$(\mathbf{k g})$ & & & &
\end{tabular}

Table 3. Carbon emission of monorail transit in construction stage.

\begin{tabular}{cccccc}
\hline & Template work & Steel work & Concrete work & Earth work & Sum \\
\hline $\begin{array}{c}\text { Carbon Emission } \\
(\mathbf{k g})\end{array}$ & 222490.5 & 1934874.1 & 14995.3 & 10300.5 & 2182660.4 \\
\hline
\end{tabular}


Table 4. Carbon emissions from transportation in material manufacturing stage.

\begin{tabular}{lcccc}
\hline & Earth & Steel & Concrete & Sum \\
\hline Carbon Emission $(\mathbf{k g})$ & 246.11 & 346.81 & 16826.78 & 17419.69 \\
\hline
\end{tabular}

Annual power consumption data and passenger and vehicle data are obtained from China Urban Rail Transit Yearbook 2019 [13] and the carbon emission of one-year operation of the monorail line is $333633.8 \mathrm{~kg}$. Assuming the life cycle of monorail is 100 years. Carbon emission of Chongqing monorail Line 2 is $1063884 \mathrm{~kg}$ per kilometer.

The carbon emission of structure demolition mainly comes from the on-site demolition process. The total concrete volume of $1 \mathrm{~km}$ was calculated before as 4736.36 $\mathrm{m}^{3}$. Since the carbon emission per cubic meter of concrete removal is $69.82 \mathrm{~kg}$ [4], we can obtain that the total carbon emission in the demolition process is $330692.66 \mathrm{~kg}$. According to the assumption of transportation of the removed material, carbon emission from this process is $16826.78 \mathrm{~kg}$.

Based on the above calculation, the whole life-cycle carbon emission of $1 \mathrm{~km}$ monorail transit is shown in the following table:

Table 5. Life cycle carbon emissions of monorail transit.

\begin{tabular}{cccccc}
\hline & $\begin{array}{c}\text { Materials } \\
\text { Manufacturing Stage }\end{array}$ & $\begin{array}{c}\text { Construction } \\
\text { Stage }\end{array}$ & $\begin{array}{c}\text { Operation } \\
\text { Stage }\end{array}$ & $\begin{array}{c}\text { Demolition } \\
\text { Stage }\end{array}$ & Sum \\
\hline $\begin{array}{c}\text { Carbon Emission } \\
(\mathbf{k g})\end{array}$ & 2659720.5 & 2200080.09 & 1063884 & 347519.44 & 6271204.03 \\
\hline
\end{tabular}

\section{Operation stage carbon emissions of different urban rail transit modes}

In this stage, we used two new units, passenger kilometers traveled (PKT) and vehicle kilometers traveled (VKT). Data from China Urban Rail Transit Yearbook 2019 [13] are used. In order to eliminate the influence of geographical factors, the operation data of rail transits in multiple cities are compared in this paper. The energy consumption data of monorail transit - metro (Chongqing), metro - maglev transit (Changsha), metro - maglev -APM (Shanghai), metro - tram (Shenyang), metro - light rail (Changchun), metro - rapid rail transit (Qingdao) and metro -APM (Guangzhou) during the operation stages are included. Then the carbon emission factor of electric power is considered to calculate the carbon emissions. The results are shown in Figure 4 to Figure 11. The unmarked bars in Figure 4 to Figure 11 represent local subways. Figure 3 shows the section of a typical subway tunnel. It can be seen that the section size is much larger than that of the monorail bridge guideway.

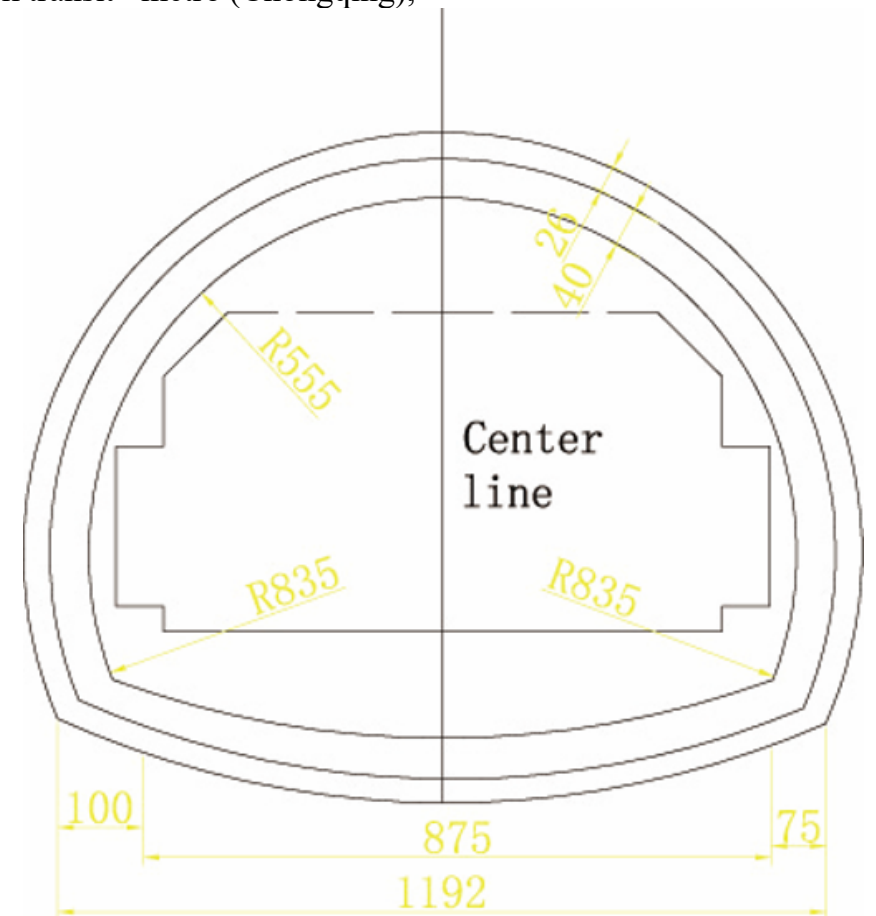

Figure 3. Typical subway tunnel cross section (Unit: $\mathrm{cm}$ ). 


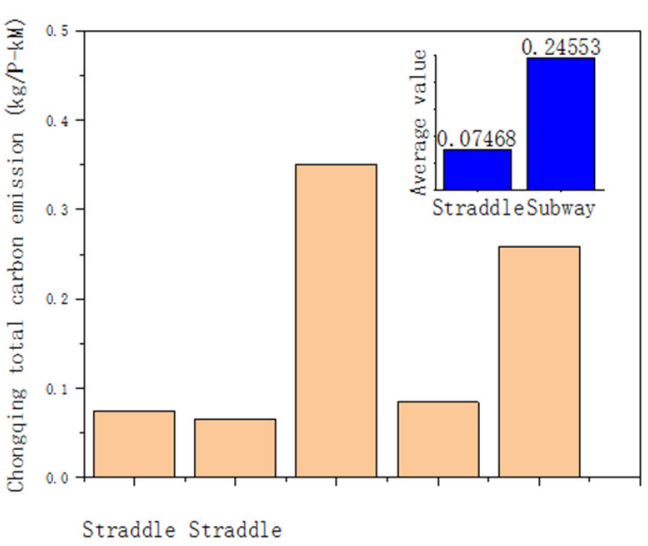

(a) PKT

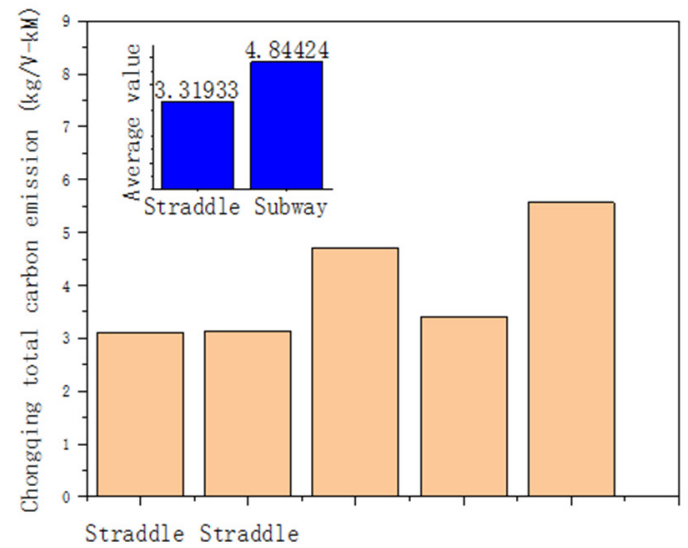

(b) VKT

Figure 4. Carbon emission comparison in Chongqing.

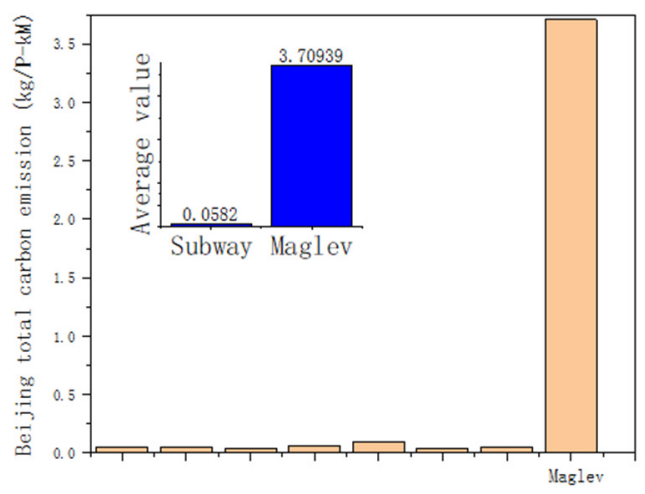

(a) PKT

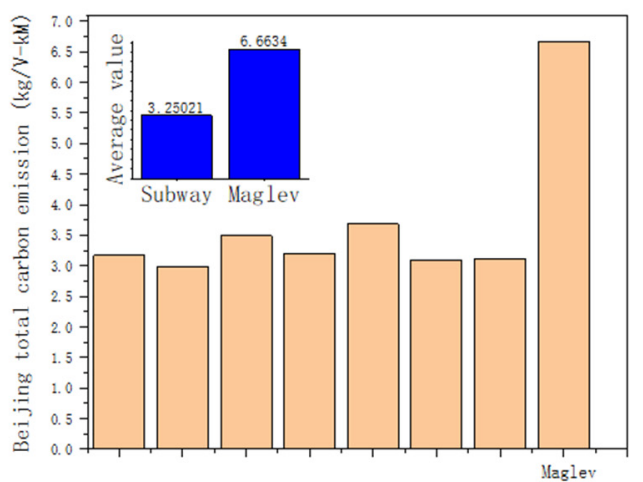

(b) VKT

Figure 5. Carbon emission comparison in Beijing.

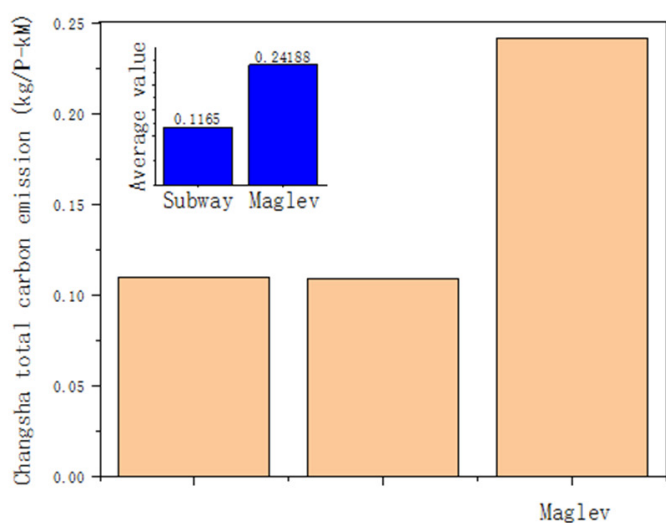

(a) PKT

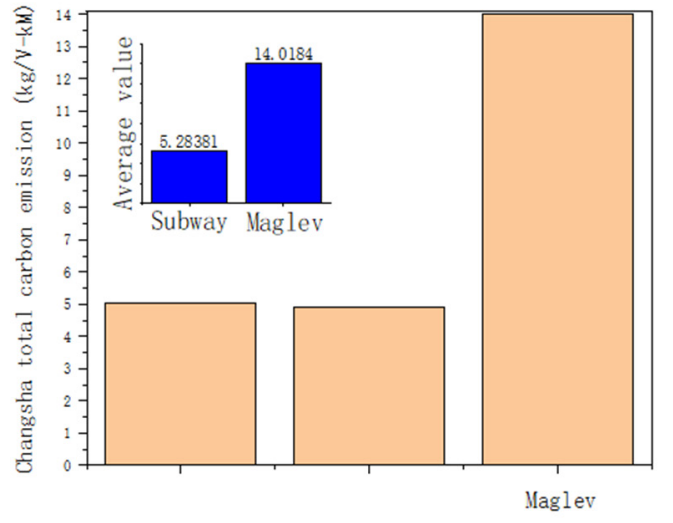

(b) VKT

Figure 6. Carbon emission comparison in Changsha. 


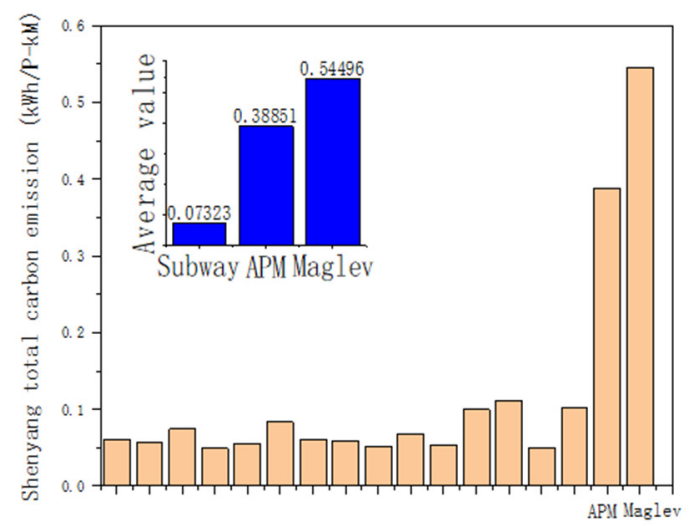

(a) PKT

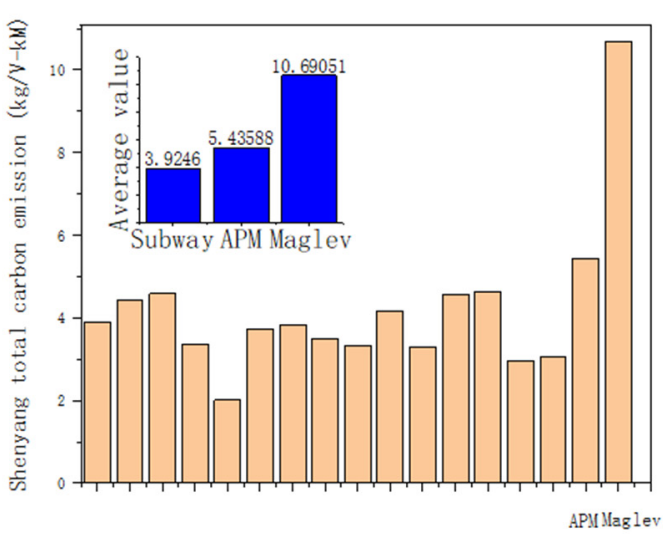

(b) VKT

Figure 7. Carbon emission comparison in Shanghai.

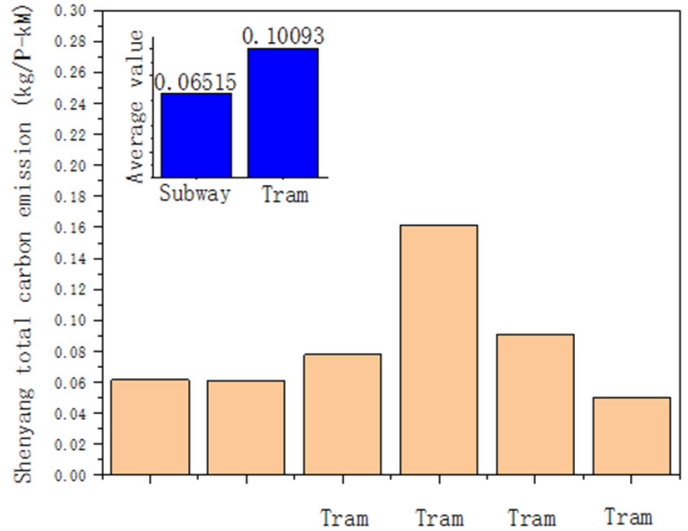

(a) PKT

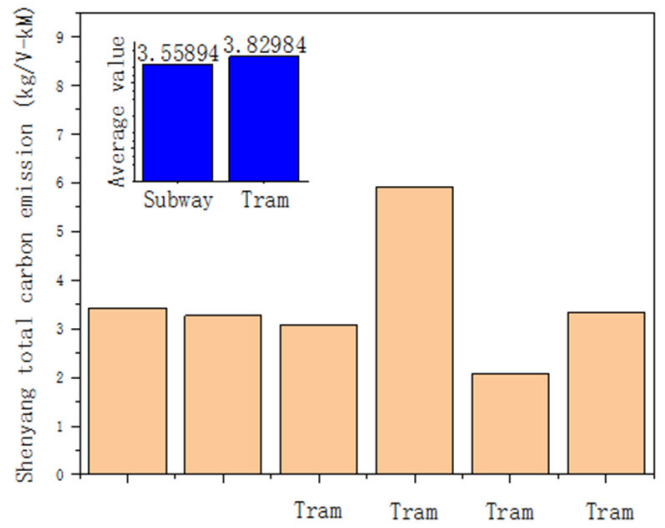

(b) VKT

Figure 8. Carbon emission comparison in Shenyang.

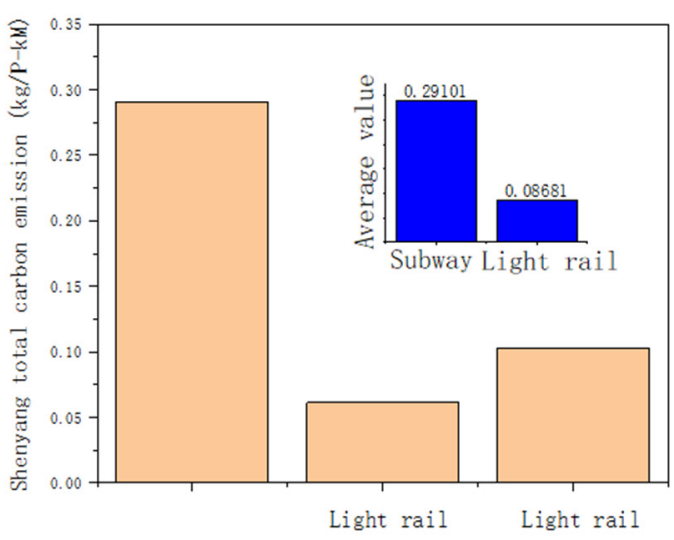

(a) PKT

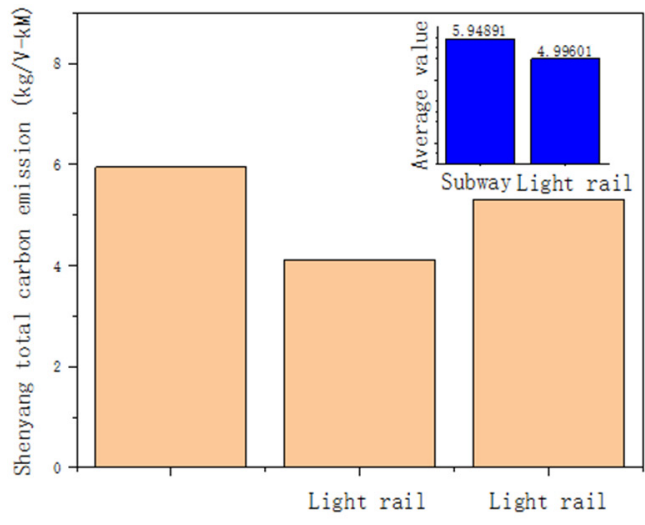

(b) VKT

Figure 9. Carbon emission comparison in Changchun. 


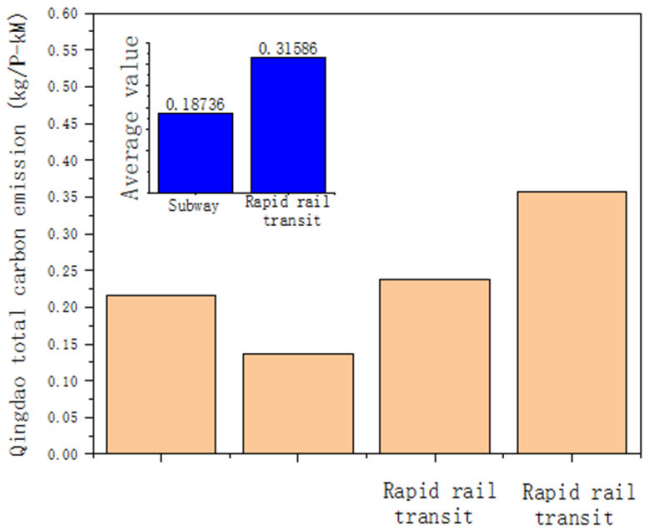

(a) PKT

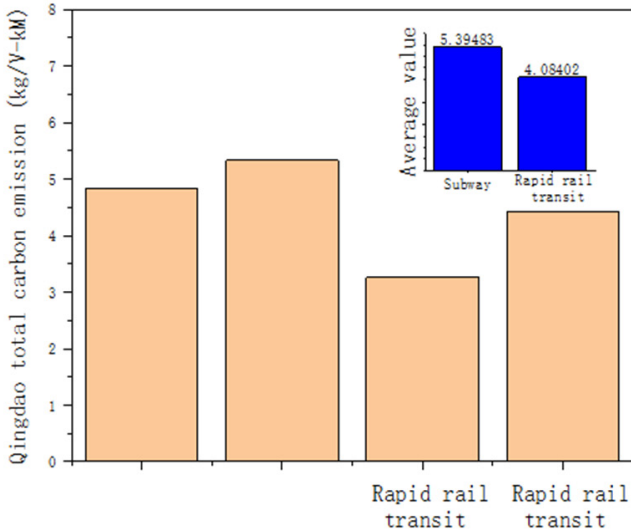

(b) VKT

Figure 10. Carbon emission comparison in Qingdao.

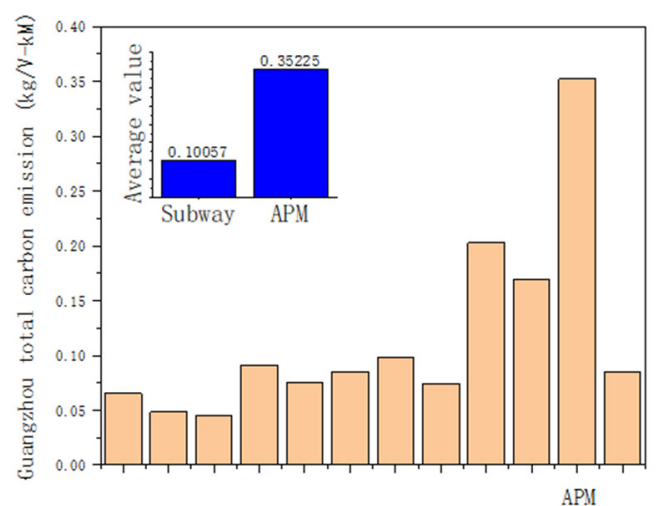

(a) PKT

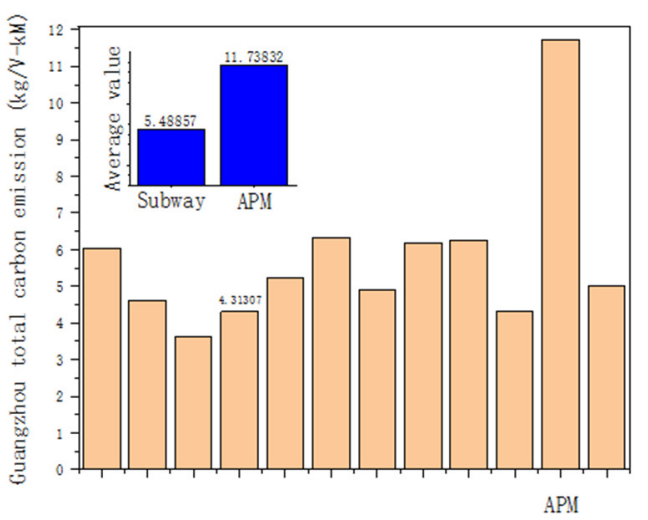

(b) VKT

Figure 11. Carbon emission comparison in Guangzhou.

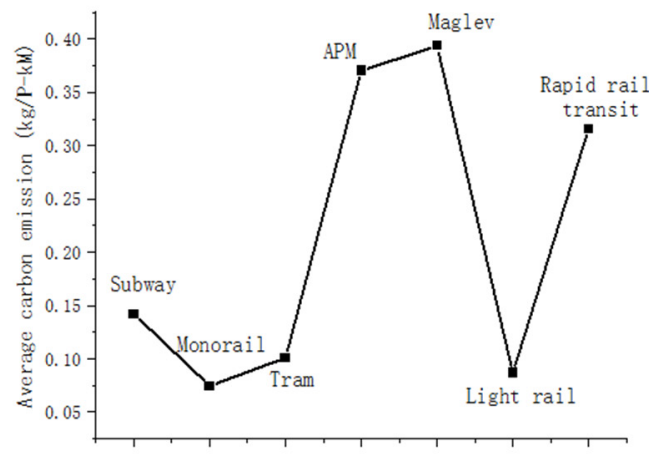

(a) PKT

Figure 12. Average carbon emission.

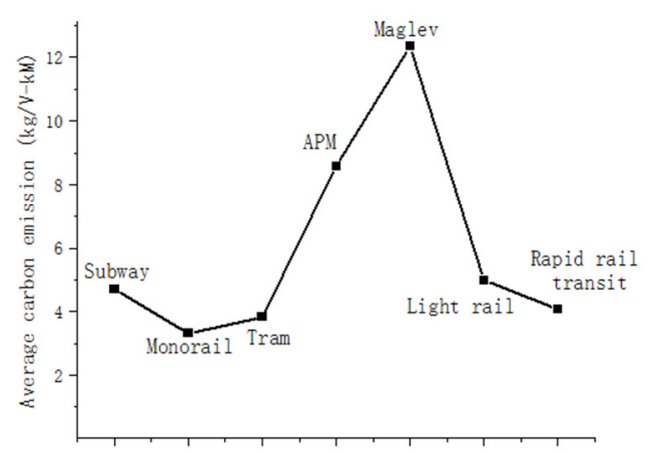

(b) VKT
Subway is still the main rail transit form in each city. It can be seen that the carbon emissions (PKT and VKT) of Chongqing monorail transit during operation are much smaller than those of local subways. According to the data of Beijing and Changsha, we find that the carbon emission of maglev is much higher than that of subway, and the VKT indexes of the two maglev lines are more than 10 . According to the data of Shanghai, we find carbon emissions of the APM line are between subway and maglev traffic, but VKT index is also over 5 . As can be seen from the data of Guangzhou, the VKT index of APM is more than 11, almost reaching the carbon emission of maglev. In addition, we can also see that the carbon emission of tram operation is slightly higher than that of subway, while the carbon emission of light rail is lower than that of subway. The PKT index of urban rapid rail transit is higher than that of subway, while the VKT index is lower than that of subway. Compared with other cities, the PKT index of Beijing subway is the lowest, which also reflects the congestion degree of Beijing subway vehicles. The number of passengers in the same vehicle increases greatly, leading to the low per capita value. As shown in 
Figure 12, for different forms of rail transit in various cities, the ranking of PKT index from small to large is monorail, light rail, tram, subway, APM and Maglev. For VKT indicators, the ascending order is monorail, tram, light rail, subway, APM and maglev.

\section{Conclusion}

The final results show that the carbon emissions from the $1 \mathrm{~km}$ length monorail are 6271.204 tons. Among them, carbon emission from the material manufacturing stage is 265.972 tons; carbon emission from the construction stage is 2,200.08 tons; carbon emission of the 100-year operation stage is 1063.884 tons, and the carbon emission in the demolition stage is 347.519 tons.

By comparing the carbon emissions in the operation stage, it is found that the PKT index and VKT index of Chongqing monorail transportation are 0.07468 and 3.31933 respectively, far lower than those of subways in the same city. For PKT indicators of other rail transit modes, from small to large, they are light rail, tram, subway, APM and maglev. As for VKT indicators, from small to large, they are tram, light rail, subway, APM and maglev. Compared with other cities, Beijing's metro has the lowest PKT index.

\section{Acknowledgments}

Authors wish to express their gratitude to the National Natural Science Foundation of China (Grants No. 51727813).

\section{References}

1. http://www.gov.cn/guowuyuan/zfgzbg.htm.

2. Zhang HX 2017 Research on $\mathrm{CO} 2$ emissions and reduction potential in China's transport sector (Doctor dissertation). North China Electric Power University, Beijing.

3. Shen XP 2018 Study on Calculation Theory and Application of Carbon Emission Reduction of Urban Rail Transit - taking Beijing as an example (Doctor dissertation). Beijing Jiaotong University, Beijing.

4. $\mathrm{Xu}, \mathrm{S} 2012$ Life cycle carbon emission of bridges with different structural materials (Doctoral dissertation). Wuhan university of technology, Wuhan, Hubei.

5. Guo YG, Lin FC, Bai YQ and Wu MM 2009 The decomposition research on energy-related carbon emissions of Shanhai Environ. Poll. Control. 9 6881.

6. IPCC 2006, 2006 IPCC Guidelines for National Greenhouse Gas Inventories.

7. Ma, ZH and Pan ZQ 1999 China coal power chain greenhouse gas emission coefficient and its comparison with nuclear power chain Chin $\mathrm{J} \mathrm{Nucl}$ Sci Eng. 3 268-74.

8. Gong ZQ and Zhang ZH 2004 Quantitative assessment of the embodied environmental profile of building materials J Tsinghua Univ (Sci \& Tech). 44 1209-13.

9. Gong ZQ and Zhang ZH 2004 A Study on embodied environmental profile during the life cycle of cement Chin Civil Eng J. 5 86-91.

10. Gong, Z 2004 Quantitative evaluation of the materialization environment in the life cycle of building materials (Doctoral dissertation). Tsinghua University, Beijing.

11. Li X, Wang S and Kong X 2011 Life cycle environmental impact assessment of premixed concrete Chin Civil Eng J. 1 132-38.

12. Li L 2003 The guideway beam design for Chongqing monorail system Urban Mass Trans. 6 88-93.

13. Editorial Committee of the Yearbook of China Association of Metros 2019 China Urban Rail Transit Almanac 2019. Shanghai Bookstore Publishing House. 